\title{
Reality of Big Data Adoption in Supply Chain for Sustainable Manufacturing SMEs
}

\author{
Satya Shah \\ Applied Engineering and Management \\ Faculty of Engineering \& Science, University of Greenwich \\ Chatham, United Kingdom \\ s.shah@gre.ac.uk
}

\begin{abstract}
The paper provides a literature review of Big Data Application (BDA) in Sustainable Manufacturing (SM) as focus of supply chain management. First of all, the concept of Big Data (BD) is explained followed by focusing on the dimensions and the potential of BD. It discusses the principle of SM, which is identified by literature as world-class sustainable manufacturing (WCSM). The literature review critically indicates differences and similarities between literatures in the research area to generate an entire understanding of the topic. Proper literature is provided to investigate the following aspects: utilization of $\mathrm{BDA}$ in manufacturing, BDA in manufacturing processes, principle of servitisiation, logistics and supplier integration, decision making processes and forecasting and finally sustainable aspects. Resulting research gaps are summarized and clustered to identify common gaps. Finally, the conclusion outlines cognitions provided by this literature review. The aim of this paper is to provide a literature review about BDA in SM as part of supply chain management to provide a general understanding of the topic and to identify common research gaps for further research projects. For achieving the aim some objectives have to be fulfilled. The concept of BD has to be explained first, before outlining the importance and the advantages of BDA. The meaning of SM is explained afterwards. A critical analysis of literature that combines both aspects leads to the understanding of BDA in Sustainable Manufacturing.
\end{abstract}

Keywords-Big Data; Sustainable Manufacturing; Supply Chain Management; Big Data Application, Manufacturing SMEs

\section{INTRODUCTION}

Big Data (BD) became one of the most investigated research topics in the past years and highly increased the attention of practitioners. The development of technology and especially the improvements in IT enables information sharing between different participants in a network. A supply chain network within a business sector could be such a network. The supply chain network consists of several partners who need to exchange information whether it is internal within a company or whether there are external information flows between business partners to increase profitability, efficiency and productivity [1]. This literature review concerns Big Data Applications (BDA) in Sustainable Manufacturing (SM) as part of supply chain management. It is not possible to consider BDA in all stages of a supply chain in depth at the same time. Therefore, the focus is set to a manufacturer point of view in a supply

\author{
Jan Wiese
Applied Engineering and Management \\ Jan Wiese
Applied Engineering and Management \\ Faculty of Engineering \& Science, University of Greenwich \\ Chatham, United Kingdom \\ j.wiese@gre.ac.uk
}

chain. Firstly, the concept of Big Data (BD) is explored based on the key dimensions and the advantages of the big data applications (BDA). The authors also aim to present the principles of sustainable manufacturing identified within literature as world-class manufacturing (WCM) and world class sustainable manufacturing (WCSM). The paper further discusses sustainability outlined within manufacturing as part of supply chain network. Finally, the paper focuses towards the key literature within the research area to provide different approaches of BDA in SM and to generate further understanding of this topic.

\section{LITERATURE REVIEW}

The literature study of the paper focuses towards three important concepts within the area of big data and big data applications, the concepts of Big Data and Supply Chain management; big data applications in manufacturing and that of sustainable manufacturing. It identifies areas for further research based upon best practices in the current market. It will ultimately form the basis for the establishment of a proposed framework of considerations for leaders within manufacturing environments to enable them the best technological advancements to be adopted within their environments in future.

\section{A. Big Data Applications (BDA)}

The concept of BD is considered as a technology concept, which is based on globalization, vast developments in virtual communications and cross-linked devices or processes. BDA are tools or methods, which cover the concept of big data. Big data analytics describes basically a process to evaluate and synthesize data sets, which has been called 'data mining' in historical context, and to convert it to more meaningful information like knowledge or competitive advantages for the benefits of the company. Hence, big data discuss applying the principle of BD to a specific business area. BDA is needed to handle the high amounts of data in its different dimensions. Data is created mainly by social media, mobile devices, automatic identification technologies (e.g. Radio-Frequency Identification (RFID) and Bluetooth) and cloud based platforms [2]. 


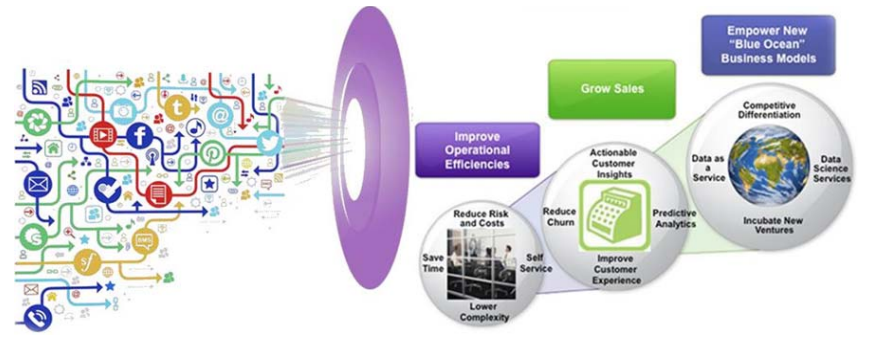

Fig. 1 Principle of BDA [3].

Unorganized facts need to be processed and streamed to get access to different types of data. Big data analytics is applied to process and organize gathered data to structure them to a given context. Therefore, big data analytics is mentioned as the utilization of understanding. Existing data need to be converted into value adding information. Figure 1 indicates the concept in a descriptive way. Unstructured data is streamed in real-time and important information are collected to proceed them for improvements in operations, to increase efficiency, grow sales and empower new business models [2]. Big data consists of different dimensions of data. Two more definitions of Big data are provided to introduce those dimensions.

- "Big data is high-volume, high-velocity and highvariety information assets that demand cost-effective, innovative forms of information processing for enhanced insight and decision making" [4].

- "Big Data is a phenomenon defined by the rapid acceleration in the expanding volume of high velocity, complex, and diverse types of data. Big Data is often defined along three dimensions - volume, velocity, and variety" [5].

\section{B. Big Data and Supply Chain Management}

The concept and the study of big data and supply chain management has been the focus of the research community for number of years. However, while the use and adoption of big data practices has been in diverse areas of retails, technology, finance, and production; other researchers have more recently started to apply the practices of big data in the wider context of supply chain management $[6,7,8]$.Thus, it has now become very important for supply chain managers to be able to evaluate the importance and relevance of big data practices to further enhance and improve upon the performance and efficiency of the organisation. It has shown in various research studies that the data provided through the practices of big data analytics allows managers to maximise different business activities including productivity, collaboration, visibility which allows the communication and relationships within all supply chain entities. Several benefits of Big Data and predictive analytics on supply chain performance have been identified $[9,10]$.
In recent research studies, many of the researchers have reviewed the literature on big data and while these studies have been able to provide insight into the field through structured reviews and classification into future research themes, apart from [10] there was no additional analyses such as bibliometric and network analyses that could help in identifying the established and emerging areas of research. Hence, the most recent studies present the use of bibliographic and network analyses, but focused on either internet of things (IoT) applications or concepts, trends and challenges of big data, rather than upon supply chain management application. Hence, this research paper we aim to address the use of the big data and supply chain management within sustainable manufacturing environments.

Research has suggested a wide use in businesses and marketing through social media and network applications data in the form of big data. There have been various research studies that focusses towards the use of data and analytical capabilities towards supply chain management practices through the focus on application and the impact of more traditional sources and forms of data to more advanced analytical techniques and tools to facilitate the planning and delivery of supply chain activities. Other studies recommend towards the use of these practices on wider interaction of supply chain management [10]. Similarly, earlier research also has presented the impact of big data on manufacturing systems and had identified that big data applications are crucial towards the data modelling, storage and the analytics within advanced manufacturing applications [11]. Studies by [12] derived that it was crucial to monitor and control the quality of data within the supply chain processes. The research suggested that supply chain professionals are challenged with new forms and types of data allowing them to be able to present and analyse the data in better ways. This further challenged other organisations to adopt and use data analytics applications including that of predictive analysis, data science methods and big data applications to improve and enhance supply chain performance within the structure. As presented earlier within the paper, the research of big data and social media have not been explored in detail in the context of supply chain management. Studies proposed analytical frameworks through which supply chain tweets could be analysed and hence the use of twitter function within the context of supply chain could be explored [10].

There has been number of research arguments presented that suggests that competition no longer exists within intrafirms or external to the organisation only, but between the entirety of the supply chain due to increased pressures upon organisations to deliver the products and services within the market place. Hence, due to this changing demand within the markets, managers and supply chain operators have to identify and adopt new practices towards their competitive edge and be able to evaluate their strategies within the 
supply chain more effectively. This was not effectively achievable previously, however due to the technological advancements and that of different data management tools, it allows firms to operate and compete in a very demanding and competitive market. Supply chain professionals are using these advanced tools and methods through data management practices to gain more exposure and advantage through supporting different supply chain functions such as inventory management and control, production performance measurements, and further improvements within the overall supply chain. Because of this changing demand and shift within the markets, many of the firms are now challenged with vast amounts of data and are using advanced data management tools to gain competitive advantages. Similar research presented that many of these firms are now changing the way business functions are carried out to achieve throughput and performance through the concept of big data applications. Research studies suggested that due to the vast popularity and adoption of data management practices many of the key performance measures and differentiation will rely on that of the company's usage of big data tools within the market place [10].

\section{Sustainable Manufacturing}

Sustainable manufacturing combines the needs of sustainability and manufacturing, which are outlined in its constituent parts, before introducing the concepts of worldclass manufacturing (WCM) and world-class sustainable manufacturing (WCSM). Moreover, key enablers of sustainable manufacturing are going to be explored within this paper.

Supply chains describe the process of producing any kind of product beginning with the raw materials to the end customer. The manufacturer is a part of a supply chain and is responsible for adding value to the product with processes or services. Within the supply chain the manufacturer is linked to a supplier of semi-finished goods or even raw material supplier via inbound logistics and on the other side with a retailer or the customer itself to deliver finished goods via outbound logistics. This literature review focusses on the manufacturing aspect of a supply chain through the key linkage of the aspect with big data application as shown later within the paper.

Literature links sustainability and manufacturing by explaining WCM first before deriving WCSM. WCM is separated from conventional manufacturing. It clarifies the important aspects of WCM as supplier relationship, lean operations, total quality, total productive maintenance, employee involvements and group technologies [13]. Additionally, it mentions work force management, processflow management, top management commitment, supplier relationship, work attitudes, feedback, customer relationship, statistical control and product design process as components of WCM [14]. Based on WCM, WCSM can be derived. "Sustainable manufacturing involves green product design, green procurement, green technology and green production" [15]. A validated WCSM framework is provided to "define a model for adoption by sustainable manufacturing enterprises" as well as to test the impact of manufacturing systems to social, environmental and economic performance [16]. So, WCSM is willing to combine superior business performance while satisfying the needs of SM at the same time. SM is also defined as decreasing negative impacts to the environment by manufacturing processes that conserve energy as well as resources. In addition, manufacturing need to fulfil the need of safety for both the commodities and consumers [17]. In order to realize SM specific key enablers like accountability, ethnic background, technology and educations have to be identified. Hence, if a company is willing to implement SM, it is very important to focus on those aspects [18]. Furthermore, a framework of nine different key enablers for SM are discovered: business models; international issues; performance measurements; reconfigurable manufacturing systems; innovative products; manufacturing strategies; reconfigurable manufacturing systems; contemporary issues; flexible organisation management and manufacturing strategies [19]. Another paper concentrates on SM from an economic point of view to give advises how to implement and measure sustainable aspects within an enterprise and to remain competitiveness at the same time [20]. Moreover, the authors have expanded their approach to a general index that is capable to measure sustainable developments of social, environmental and economic aspects within companies [20].

\section{Big Data Applications in Sustainable Manufacturing}

After the key aspects of the research area have been clarified; Big Data Applications (BDA) and Sustainable Manufacturing (SM) can be linked. Important aspects have been identified as the utilization of BDA in manufacturing, BDA in manufacturing processes, logistics and supplier integration with an intelligent inventory control and materials sourcing, decision making processes and forecasting of demand as well as sustainable aspects of BDA.

Practical aspects of implementation of BD are provided [21]. They provide a literature review of SM and Industry 4.0 as part of the Internet of Things (IoT), which is closely related to $\mathrm{BD}$ and is a kind of a basic requirement for the application of BD. They are presenting a cross-linked smart network to raise data from processes and information, which automatically enables opportunities to apply sustainability to the process of value adding in both micro and macro perspective. The macro perspective describes the whole supply chain and the products within its product life cycle. On the contrary, the micro perspective concentrates on the manufacturer as one participant of a supply chain linked to other players. Hence, the macro perspective will be 
explained first, before considering the micro perspective in depth, which is related to the implementation of a manufacturer within a supply chain [21]. Industry 4.0 is determined by three different dimensions. Beginning with the horizontal integration, which stands for linking internal processes of a company as well as connections between different companies across the entire value creation network. Connecting different value chains is important to get a full understanding of processes whether they are internal or external related to the product. The end-to-end engineering is the second dimension. Across the "entire product life cycle, it describes the intelligent cross-linking and digitalization of value creation modules throughout all phases of a product life cycle: from raw material acquisition to manufacturing system, product use, and the product end of life" [21]. The third dimension describes the vertical integration between different hierarchical levels of value creation.

\section{E. Big Data Application and Manufacturing Process}

As seen through research studies, Industry 4.0 is a basic requirement of $\mathrm{BDA}$ in manufacturing processes. The micro perspective is about cross-linking all processes, machines, and divisions within the company to monitor the product quality in real-time. The value creation modules are linked via the cloud gathering all data, which are created by sensors, measuring tools or process parameter [21]. "Future manufacturing systems will need to process large amounts of complex data which are provided to workers for maintaining the proper function and desired production performance due to a rising demand on visibility and vertical integration of factory floor devices with higher level systems." [22]. Data could be internal, external or third party external data [1]. However, a company should always try to understand and evaluate the internal data first, before concentrating on external data [11]. The utilization of big data applications in predictive manufacturing is investigated [22]. As a result, the existing bottlenecks within the manufacturing process or the demand itself have to be streamlined by improving forecasting opportunities. Big data has to be fully understood in both storage and analysing the data. For instance, an analytical model has been provided to "predict power consumption in manufacturing processes" [11, 23].

In addition, it is worked out on different aspects that influence the supply chain as 'game changers': big data applications, additive manufacturing and borderless supply chains are mentioned in this context [24]. They illustrate the increase of data by giving an example of the exponential increase of data creation mentioning that $90 \%$ of data ever generated by mankind was created within the past two years. Concluding, companies have to be prepared to implement big data in their supply chains, otherwise they run the risk to lose market share or be even eliminated from the market. As a conclusion three aspects have to be mastered: the right players need to possess the right roles in correlation with the right relationships. For manufacturing companies, it is very important to define when and how to implement big data applications [24]. A framework of a new way to generate competitive advantage based on big data has been proposed [25]. The big data strategy should combine the purposes of big data as well as servitization, which is described as creation of value by adding services to a specific product [26]. Therefore, the point of 'information' is added to both conventional aspects of servitisiation 'product' and 'service'. In this article big data is defined by $5 \mathrm{~V}$ 's; however, four of them are just called "technical challenges" [25], which lead to a contradiction to the definitions of big data earlier within the paper. The definitions and the approaches based on those consider the different dimensions of big data as equally entitled without ranking them.

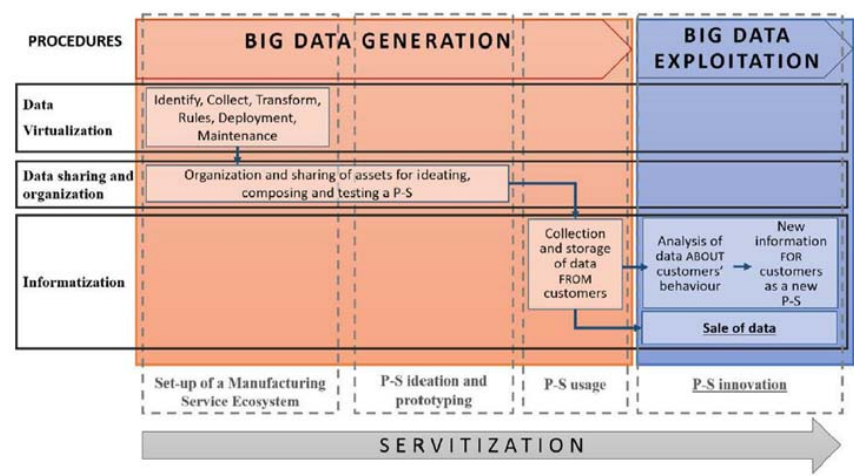

Fig. 2 Macro perspective of Industry 4.0 [21].

\section{STUDY LIMITATIONS AND RECOMMENDATIONS}

The paper identifies research gaps of all reviewed literature and aims to summarise the common gaps for further research. Real-time analytics related to social media and mobile apps are becoming an important research area were identified [27]. In addition, further research need to be done to develop advanced data storage and data processing technologies as well as advanced solution for data acquisition and data visualization [11]. It is also concluded that more approaches have to be figured out to adjust supply chains for implementing big data and further research needs to focus on the development theories to handle data in cross functional ways [7]. Moreover, research in issues of management and operations are lacking and require further exploration.

The future focus on using Big Data in advanced manufacturing technology should be redefined by further research, because big data could address more matters and problems than expected [8]. Capabilities of big data applications in world-class sustainable manufacturing need to be explored. Hence, new innovations can be made based on implementation of big data applications in world-class sustainable manufacturing. Additionally, the research on 
aspects like complexity of a product or the capacity that could be integrated by organisations need to be expanded by other researchers. Another important aspect provided identifies the need of a deeper understanding of how the world-class sustainable manufacturing framework is impacted by national and global cultures and future research needs to answer this [16].

It is argued that less information about concrete solutions to practitioners to apply BDA is available [25]. More research needs to be done to suggest practical ways of how to handle such volumes of data efficiently in a dynamic manner. Based on the described gaps of the several articles a common gap can be identified. Even though sustainable manufacturing and big data applications are linked to the environmental aspects of sustainability, it is evident that further research need to be undertaken to consider social and economic aspects of sustainability in sustainable manufacturing linked to big data applications. Furthermore, big data applications is still identified as one of the most important aspects in manufacturing with regard to competitive advantage. Hence, it is important to investigate and develop more approaches to apply the following theories to commercial practices.

Future work investigating the following impact is needed, and highly valuable and informative for holistically understanding the overall nature of the contemporary firm and its place in both its competitive market and larger global context. The authors note that the theoretical areas discussed within this paper are not exclusive or exhaustive, and future research within this area can inspire connections to additional extant and relevant theoretical research streams. The discussed theory streams, with their focus on different areas of the firm, suggest that mixed-methods research would be highly beneficial and possibly necessary, in developing the well-rounded picture between big data and predictive analytics and sustainable SCM outcomes. The highlighted theoretical areas provide a solid foundation for scholars seeking to develop novel theories and broaden research linking these two critical strategic areas in supply chain management. Such work would additionally inform practitioners in examining organizational characteristics and their impact upon big data and predictive analytics and supply chain management sustainability and the relationship between these areas. As big data and predictive analytics is acknowledged as a competitive necessity in the supply chain, future research of its impact upon all firm performance outcomes is highly valuable and will wisely guide scholarly research of sustainable supply chain management for the conceivable future [12].

\section{CONCLUSION}

The aim of this paper is to provide a wider understanding of big data in sustainable manufacturing and to identify common gaps for further research. The concept of big data has been identified as a technology concept, which uses big data applications to convert unstructured data into knowledge to enable competitive advantage and therefore to increase revenues. Literature agrees in big data having huge potential for a revolutionizing impact on management structures and forecasting methods.

Sustainable manufacturing satisfies the needs of a sustainable development and world-class manufacturing (WCM). The focus of this paper is set to the manufacturer within a supply chain. Hence, the micro perspective has been mentioned as most important to present a template of a smart factory and how to structure manufacturing based on big data applications. Big Data Applications help to streamline existing bottlenecks and to monitor product quality in real-time, which lead to an increase in efficiency within manufacturing processes. The principle of servitization is introduced to offer manufacturer opportunities to generate revenues that are not directly linked to new product developments. Logistics and suppliers are directly linked to the cloud to get access to the information flow. Hence, suppliers are able to react instantly on fluctuations in demand. Moreover, it has been worked out that the internal logistics can stream the inbound and outbound deliveries in real-time as well.

However, the implementation of Big Data Application in Sustainable manufacturing is challenging and the potential to revolutionize manufacturing and the impact on decision making processes, increasing profitability and efficiency is massive. Literature identifies smarter decision making and forecasting methods enabled by BDA as the most important aspect in manufacturing. Finally, the management board needs to have access to all important data related to processes and the company itself. The maturity of big data analytics investigating gathered data defines the competitive advantage the company is able to gain. Hence, it is necessary for the management to implement big data applications within sustainable manufacturing to satisfy customer needs in future and to ensure long-term sustainable development. As pointed out earlier within our research study, better approaches are required to be identified by further research to apply theoretical models to practice to enable the full potential of big data applications within the manufacturing SMEs.

Acknowledgements This paper is part of an ongoing research project within the research centre and includes a preliminary study towards understanding the adoption and implementation of Big Data Application (BDA) and technological advances within manufacturing SMEs for sustainable supply chain management. The framework draws up current literature studies within this context and aims to develop more investigative based case studies within manufacturing SMEs to further develop the research framework. 


\section{REFERENCES}

[1] C. Marinagia, P. Trivellas, and D. Sakas, "The impact of Information Technology on the development of Supply Chain Competitive Advantage," Procedia - Social and Behavioral Sciences, 147, p.586-591, 2014.

[2] Wamba, S. and Akter, S. Big data analytics for supply chain management: A literature review and research agenda. Cham, Springer, 2015.

[3] Bhowmick, S, Morningtea. [Online] Available at: https://morningtea.in/customer-behavior-through-big-dataanalytics/\#prettyPhoto/2/ [Accessed 05 April 2017], 2017.

[4] Gartner, n.d. Gartner IT Glossery. [Online] Available at: http://www.gartner.com/it-glossary/big-data/ [Accessed 01 March 2017].

[5] C. Wilson, and J, Kerber, Demystifying Big Data, Washington DC: Tech America Foundation, 2012.

[6] H. Chen, R. Chiang and V. Storey, "Business Intelligence and Analytics: From Big Data to Big Impact,” MIS Quarterly, 36(4), pp. 1165-1188, 2012.

[7] Wamba, S. F. S. F. Wamba, S. Akter, A. Edwards, G, Chopin, and D. Gnanzou, "How 'big data' can make big impact: findings from a systematic review and a longitudinal case study," Int. J. Production Economics, 165, pp.234-246, 2015.

[8] R. Dubey, A. Gunasekaran, S.J. Childe, S.F. Wamba, and T. Papadopoulos, "The impact of big data on world-class sustainable manufacturing," The International Journal of Advanced Manufacturing Technology, 84(1-4), pp.631-645, 2016.

[9] T. Schoenherr, and C. Speier-Pero, "Data science, predictive analytics, and big data in supply chain management: Current state and future potential," Journal of Business Logistics, 36(1), pp.120$132,2015$.

[10] D. Mishra, A. Gunasekaran, T. Papadopoulos, and S.J. Childe, "Big Data and supply chain management: a review and bibliometric analysis," Annals of Operations Research, pp.1-24, 2016.

[11] Z. Bi and D. Cochran, "Big data analytics with applications," Journal of Management Analytics, 1(4), pp.249-265, 2014.

[12] B.T. Hazen, J.B. Skipper, J.D. Ezell, and C.A. Boone, "Big Data and predictive analytics for supply chain sustainability: A theory-driven research agenda," Computers \& Industrial Engineering, 101, pp.592$598,2016$.

[13] H. Steudel, and P. Desruelle, Manufacturing in the '90s: How to become a mean, lean world-class competitor. Van Nostrand: Reinhold Company, 1992.

[14] B. Flynn, R.G. Schroeder, E.J. Flynn, S. Sakakibara, and K.A. Bates, "World-class manufacturing project: overview and project: overview and selected results," International Journal of Operations \& Production Management, 17(7), pp.671-685, 1997.

[15] S. Vachon, "Green Supply Chain Practices and the Selection of Environmental Technologies," International Journal of Production Research, 45(18-19), p 4357-4379, 2007.

[16] R. Dubey, A. Gunasekaran, and A. Chakrabarty, "World-class sustainable manufacturing: framework and a performance measurement system," International Journal of Production Research, 53(17), p. 5207-5223, 2015.

[17] US Department of Commerce, Promoting competitiveness: Partnerships and progress of the office of manufacturing and services, s.1.: International Trade Administration, 2007.

[18] Z. Molamohamadi, and N. Ismail, "Developing a New Scheme for Sustainable Manufacturing," International Journal of Materials, Mechanics and Manufacturing, 1(1), pp.1-5, 2013.

[19] I. Garbie, "DFSME: design for sustainable manufacturing enterprises (an economic viewpoint)," International Journal of Production Research, 51(2), p.479-503, 2013.

[20] I. Garbie, "An analytical technique to model and assess sustainable development index in manufacturing enterprises," International Journal of Production Research, 52(16), p. 4876-4915, 2014

[21] T. Stock, and G. Seliger, "Opportunities of Sustainable Manufacturing in Industry 4.0," Procedia CIRP, 40, pp.536-541, 2016.
[22] J. Li, F. Tao, F.Y. Cheng, and L. Zhao, "Big Data in product lifecycle management," The International Journal of Advanced Manufacturing Technology, 81, pp.667-684, 2015.

[23] S.-J Shin, J. Woo, and S., Rachuri, "Predictive Analytics Model for Power Consumption," Procedia CIRP, 15, pp.153-158, 2014.

[24] S. Fawcett, and M. Waller, "Supply Chain Game Changers - Mega, Nano, and Virtual Trend - And Forces That Impede Supply Chain Design (i.e., Building a Winning Team)," Journal of Business Logistics, 35(3), pp.157-164, 2014.

[25] D. Opresnik, and M., Taisch, "The Value of Big Data in Servitization," International Journal of Production Economics, 165, pp. 174-184, 2015.

[26] US Department of Commerce, Promoting competitiveness: Partnerships and progress of the office of manufacturing and services, s.1.: International Trade Administration, 2007.

[27] A. Gandomi, and M. Haider, "Beyond the hype: Big data concepts, methods, and analytics," International Journal of Information Management, 35, p. 137-144, 2015. 